\title{
Genome sequencing analysis of blood cells identifies germline haplotypes strongly associated with drug resistance in osteosarcoma patients
}

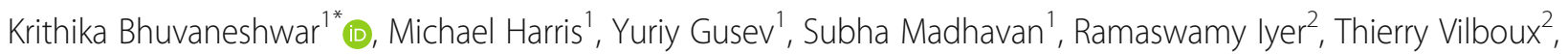
John Deeken², Elizabeth Yang ${ }^{3,4,5,6}$ and Sadhna Shankar ${ }^{3,4}$

\begin{abstract}
Background: Osteosarcoma is the most common malignant bone tumor in children. Survival remains poor among histologically poor responders, and there is a need to identify them at diagnosis to avoid delivering ineffective therapy. Genetic variation contributes to a wide range of response and toxicity related to chemotherapy. The aim of this study is to use sequencing of blood cells to identify germline haplotypes strongly associated with drug resistance in osteosarcoma patients.
\end{abstract}

Methods: We used sequencing data from two patient datasets, from Inova Hospital and the NCI TARGET. We explored the effect of mutation hotspots, in the form of haplotypes, associated with relapse outcome. We then mapped the single nucleotide polymorphisms (SNPS) in these haplotypes to genes and pathways. We also performed a targeted analysis of mutations in Drug Metabolizing Enzymes and Transporter (DMET) genes associated with tumor necrosis and survival.

Results: We found intronic and intergenic hotspot regions from 26 genes common to both the TARGET and INOVA datasets significantly associated with relapse outcome. Among significant results were mutations in genes belonging to AKR enzyme family, cell-cell adhesion biological process and the PI3K pathways; as well as variants in SLC22 family associated with both tumor necrosis and overall survival. The SNPs from our results were confirmed using Sanger sequencing. Our results included known as well as novel SNPs and haplotypes in genes associated with drug resistance.

Conclusion: We show that combining next generation sequencing data from multiple datasets and defined clinical data can better identify relevant pathway associations and clinically actionable variants, as well as provide insights into drug response mechanisms.

Keywords: Whole genome sequencing, Childhood cancers, Drug resistance, Osteosarcoma, Pharmacogenomics, Genetics

\footnotetext{
* Correspondence: kb472@georgetown.edu

${ }^{1}$ Innovation Center for Biomedical Informatics, Georgetown University

Medical Center, Washington DC, USA

Full list of author information is available at the end of the article
}

(c) The Author(s). 2019 Open Access This article is distributed under the terms of the Creative Commons Attribution 4.0 International License (http://creativecommons.org/licenses/by/4.0/), which permits unrestricted use, distribution, and reproduction in any medium, provided you give appropriate credit to the original author(s) and the source, provide a link to the Creative Commons license, and indicate if changes were made. The Creative Commons Public Domain Dedication waiver (http://creativecommons.org/publicdomain/zero/1.0/) applies to the data made available in this article, unless otherwise stated. 


\section{Background}

Osteosarcoma (OS) is the commonest malignant bone tumor in children. It accounts for about $2 \%$ of childhood cancers in the US. Approximately 800 new cases are diagnosed in the US every year, about 400 of which are in children and teens [1]. OS occurs mostly between the ages of 10 and 30. Approximately $60 \%$ of all malignant bone tumors diagnosed in the first two decades of life are osteosarcomas.

The role of adjuvant chemotherapy is well established in the treatment of osteosarcoma [2, 3]. Prior to use of systemic chemotherapy, two-year survival was less than $20 \%$ even in patients with clinically localized disease. Most recent studies report a 3-year survival of $60-70 \%$ among patients with non-metastatic disease treated with combination chemotherapy. Standard treatment for non-metastatic osteosarcoma includes neo-adjuvant chemotherapy followed by surgical resection and post-operative chemotherapy. The extent of necrosis of the primary tumor at time of definitive surgical resection is the only significant prognostic factor in patients with non-metastatic osteosarcoma. Patients with less than 10\% viable tumor at time of definitive surgery have significantly lower risk of relapse as compared to those with more than $10 \%$ viable tumor [4]. Five-year survival is $75-80 \%$ among patients with good histological response and only $45-55 \%$ among poor responders even after complete surgical resection $[5,6]$.

The most active chemotherapeutic agents against osteosarcoma include cisplatin, doxorubicin and high dose methotrexate. The Children's Oncology Group (COG) considers combination cisplatin, doxorubicin and high dose methotrexate (MAP) as standard therapy for osteosarcoma [7]. Postoperative therapy is often modified in poor responders to improve outcome, such as the use of ifosfamide and etoposide [8-10]. However, no such attempts have been successful to date. It is likely that the initial 8-12 weeks of ineffective therapy select for resistant clones and allow the cancer cells to metastasize. Changing therapy at a later time point fails to change the outcome. There is a need to identify the poor responders at time of initial diagnosis to avoid delivering ineffective pre-operative therapy. Alternative chemotherapeutic agents at initial diagnosis could potentially alter outcomes in patients expected to have poor response to standard cisplatin based chemotherapy. Thus, the key challenge is to determine the basis for response and non-response in patients at the outset and identify patients who are eligible for intensified or alternative therapy given their personal profile.

The completion of the HapMap project is a historic achievement [11]. The project identified over one million single nucleotide polymorphisms (SNPs) across the human genome, which may be at the root of the great variation seen in human health and disease. Germline genetic variation between individuals may lie at the heart of two critical questions: who is at risk to develop cancer, and how best to treat individuals once they are diagnosed. This genetic variation may account for the wide variation seen in the response and toxicity related to chemotherapeutic agents.

The pharmacogenetic differences between patients are multi-factorial [12]. One factor is polymorphism in drug targets, including cell surface receptors and target proteins. Another is polymorphism in cellular recovery mechanisms that repair cytotoxic agent-induced damage. Finally, there are polymorphisms in genes encoding proteins involved in drug pharmacokinetics, including proteins that impact drug absorption, metabolism, distribution, and elimination (ADME). Germline pharmacogenetic biomarkers have been found for a number of anticancer agents, including irinotecan, mercaptopurine, 5-flurouracil, and tamoxifen [13-16]. These studies often used a candidate gene approach, and attempted to explain a drug's efficacy or toxicity by identifying one gene and even one variant within that gene [17].

While candidate gene/single variant analysis provides important insights, there are several limitations in most published studies. The implicated alleles were often low frequency and the absolute numbers of patients with these alleles were low. Only one or few single nucleotide polymorphisms (SNPs) were examined for each gene of interest and potentially significant polymorphisms could have been missed. In this study, we applied both single SNP and multiple SNP analysis to get an enhanced understanding of genetic polymorphism in the disease.

A genome-wide approach enables examination of polymorphisms of a large number of implicated genes in multiple pathways that may impact on response to chemotherapy. With advance in technology and reduction in costs, whole-genome sequencing is now feasible with next-generation sequencing. Complete sequences of implicated genes can be analyzed to identify polymorphisms in the context of pathway datasets, rather than as individual data points. An integrative approach combining whole genome sequencing (WGS) with multiple datasets and defined clinical data can 1) better capture pathway associations, and 2) provide the opportunity for discovery of clinically actionable variants $[18,19]$.

We have previously used this integrative approach to define the pharmacogenetic profile of gemcitabine, and defined a 'sensitive' and 'resistant' genotype using the combination of pre-clinical data from the NCI60 cell lines and a genome wide association studies (GWAS) clinical dataset from a large clinical trial [20]. We now wish to expand this approach to pediatric osteosarcoma patients treated with multi-agent chemotherapy, including cisplatin, doxorubicin, and methotrexate. 
The aim of this study is to identify, test, and validate a genotype resistant to cisplatin, doxorubicin, and methotrexate, in children with osteosarcoma, using two datasets derived from clinical samples. The genetic signature that is strongly associated with drug response could be translated into clinical oncology [21] and used in the future to personalize therapy.

\section{Methods}

Whole genome sequencing data was obtained from a cohort of 15 osteosarcoma patients from the Inova Fairfax Hospital for Children. Additional sequencing data and clinical outcomes of 85 patients with osteosarcoma were obtained from the NCI TARGET dataset. The following sections describe the datasets, sample collection procedures and data analyses.

\section{Datasets}

- Inova Pediatric Group Osteosarcoma Patients (labeled 'INOVA'): Whole genome sequencing (WGS) was performed for 15 children, who are up to 21 years of age with osteosarcoma, including newly diagnosed and off therapy. Patients were recruited over a 2 year period from 2014 to 2016. Demographic, clinical outcome, chemotherapeutic exposure and pathological response data were collected for all subjects. The study was IRB approved; informed consent and assent were obtained from each child and parent as appropriate. DNA was extracted from whole blood samples, and whole genomic DNA was sequenced on an Illumina HiSeq 2500 whole genome sequencer at 30-50X coverage. Raw sequencing data were obtained in the form of Fastq [22] files.

- TARGET Osteosarcoma Dataset (labeled 'TARGET'): This is a cohort of 85 fully characterized patient cases from NCI's TARGET database for osteosarcoma (released in Feb 2015) [23, 24]. The majority of these patients were teenagers. The samples were collected at the time of diagnostic surgery. Aligned genomic data from whole blood samples were downloaded from NCI's dbGAP database [25]. Out of this 85-patient cohort, whole exome sequencing (WXS) data were available on 52 patients and WGS data were available on 33 patients. For each patient, aligned genomic data in the form of 'BAM files' short for Binary Alignment Map [26] were downloaded, decrypted and processed.

All patients were treated with standard MAP therapy. The standard MAP neo-adjuvant chemotherapy regimen is as follows: Doxorubicin (Adriamycin) $37.5 \mathrm{mg} / \mathrm{m} 2 /$ day and Cisplatin (Platinum) $60 \mathrm{mg} / \mathrm{m} 2 /$ day on days 1,2 of week 1; Methotrexate $12 \mathrm{~g} / \mathrm{m} 2$ on day 1 of week 4 , week 5 . This entire cycle is repeated week 6-10. Surgical resection with tumor necrosis data on week 12 .

\section{Processing of genomic data}

We used open source well-known best practices tools in the processing of sequencing data. The tools included Sickle [27], Bowtie2 [28], Samtools [29], Picard [30], and GATK's [31] HaplotypeCaller. After quality control, the raw sequencing data in the form of FASTQ files were aligned to the human reference genome (version hg19). Post alignment processing was done on the aligned reads, so that it will be in the right format for the subsequent step. A variant calling algorithm was applied, which mathematically checked the patient genome against the reference genome to identify variants in the form of single nucleotide polymorphisms (SNPs) or indels. The variants identified from each patient were merged into one file. Only those variants that passed quality check were chosen for further analysis. Additional file 1 shows the steps, file formats and tools in this genomic data processing, which was performed on an Amazon cloud r3.4xlarge instance.

The TARGET variants were a combination of whole-exome and whole-genome data. We applied a filtering criterion on the variants such that if all patients, or if 84 of the 85 patients had the reference allele, then the variant was rejected. The same processing steps were applied to both datasets in an effort to reduce batch effects. At the end of this filtering, the TARGET dataset had about 900,000 SNPs and the INOVA dataset had about 8 million SNPs.

\section{Outcomes of interest}

The outcomes of interest chosen were: (1) Relapse (2) Percent tumor necrosis and (3) overall survival.

Tumor necrosis following preoperative chemotherapy is the strongest prognostic factor for osteosarcoma [32]. Tumor necrosis as an outcome provides a window into the early part of drug response, while 'relapse' as outcome provides an extended view of drug response.

Relapse information was available for all the 15 INOVA patients and 85 TARGET patients. These patients also had overall survival information (Table 1).

Tumor necrosis data were available for the 15 patients from the INOVA cohort, but only for 44 out of 85 patients from the TARGET cohort. Patients with tumor necrosis greater than $90 \%$ at the time of resection were

Table 1 Summary of patients showing the number of patients who relapsed and were relapse-free

\begin{tabular}{llll}
\hline Dataset & \# Relapse & \# Relapse-free & Total \# of patients \\
\hline TARGET & 39 & 46 & 85 \\
INOVA & 3 & 12 & 15 \\
\hline
\end{tabular}


'Good responders'; patients with tumor necrosis $<=90 \%$ were 'Poor responders' (Table 2).

\section{Methods for SNP analysis}

Two analyses were performed, shown in Fig. 1.

\section{Analysis 1: hotspots associated with relapse}

We analyzed the INOVA and TARGET datasets separately to look for hotspots associated with relapse outcome. Hotspots are regions in the genome that have multiple co-occurring mutations in the same or close-by regions [33]. In our analysis, we looked for hotspots, in terms of haplotypes, which are groups of markers (SNPs) that are inherited together [34]. Once the significant haplotypes associated with outcome were identified, we then looked for haplotypes overlapping between the two datasets.

There are several advantages to grouping SNPs: it reduces the number of tests, making it easier to reject the null hypothesis, offering more power to the analysis; SNPs in a haplotype block (haploblock) are inherited together; the markers (SNPs) are often closely located and will be in linkage disequilibrium (LD); increased robustness in statistical testing; groups of SNPs affecting outcome are more biologically relevant than a single SNP affecting outcome [35].

For this study, we performed haplotype based association test analysis using the PLINK tool $[36,37]$. For each dataset, the tool identified haplotypes significantly associated with relapse outcome ( $p$ value $<=0.05$ ). Using chromosome location as criteria, we looked for overlapping haplotypes between the two datasets. We looked for partial or complete overlap in the chromosome location; hence the SNPs in these common haplotypes may or may not be the same. Looking for overlap in two independent datasets reduces the chances of randomly occurring haplotypes and helps eliminate false positives.

The SNPs in these common haplotypes were then mapped to genes and pathways to enable downstream system biology analysis to give insights into drug response mechanisms.

\section{Analysis 2: targeted analysis of variants in DMET genes associated with tumor necrosis and survival}

We performed a targeted analysis of mutations in the genes involved in drug absorption, metabolism,

Table 2 Summary of patients with Tumor necrosis information. Good Responders: > 90\% tumor necrosis; Poor Responders: $\leq$ 90\% tumor necrosis

\begin{tabular}{llll}
\hline Dataset & \# Poor Responders & \# Good Responders & Total \# of patients \\
\hline TARGET & 26 & 18 & 44 \\
INOVA & 9 & 6 & 15 \\
\hline
\end{tabular}

distribution, and elimination (ADME), also known as Drug Metabolizing Enzymes and Transporters (DMET). The words DMET and ADME are used interchangeably in this manuscript. We explored their association with tumor necrosis using machine learning methods.

Among the 85 TARGET patients, only 44 had clinical data available on tumor necrosis (Table 1). All the 15 INOVA patients had data available on tumor necrosis. Since the sample size would be small and there would not be enough power to obtain statistically significant results, we merged the two datasets to get a total of 59 patients (referred to as the 'TARGET+INOVA' cohort).

Before starting the analysis, we tested the data for batch effects. We performed a principal component analysis (PCA) on variants in DMET genes (Additional file 2) using the $\mathrm{R}$ statistical platform (https://cran.r-project. org/). We found a clear batch effect due to the merging of the two datasets. We have accounted for this batch effect in our analysis.

From the TARGET + INOVA cohort, we extracted 36,504 variants in DMET genes. We binned the data into 0 (indicating no mutation) and 1 (indicating presence of mutation). $85 \%$ of these data were randomly set as training set and the rest $15 \%$ were set as an independent validation set using the caret package [38] (seed of 7) in R. Several filters were applied on the training set so that only SNPs with the most variability were chosen for the analysis. At the end of all the filtering, we were left with 4543 SNPs for analysis.

For each of the 4543 variants, we created two generalized linear models (GLMs) with tumor necrosis as outcome variable: one with the variant and adjusting for the dataset to control for batch effect; and second one specified without the variant. This allowed us to perform logistic regression analysis to find those variants most associated with tumor necrosis outcome. We then used analysis of variance (ANOVA) to compare the two models to obtain a $p$-value based on chi-square distribution (described in Additional file 2). The $p$-values from this test were adjusted for multiple testing using the Benjamini Hochberg approach to control the false discovery rate (FDR) [39]. The significant variants $(p$ value $<0.05)$ from this analysis were annotated using SnpEff [40] variant annotation tool. The annotations were used to sub-divide these SNPs based on their impact into high, moderate, low impact, and modifiers (non-coding regions).

We built a Random Forest predictive model with these significant variants with 20 fold cross validation (seed 260), and performed a prediction on the independent validation set (block diagram shown in Additional file 2).

We also performed survival analysis on the significant variants to assess their impact on overall survival. The association with survival was tested using the log rank 


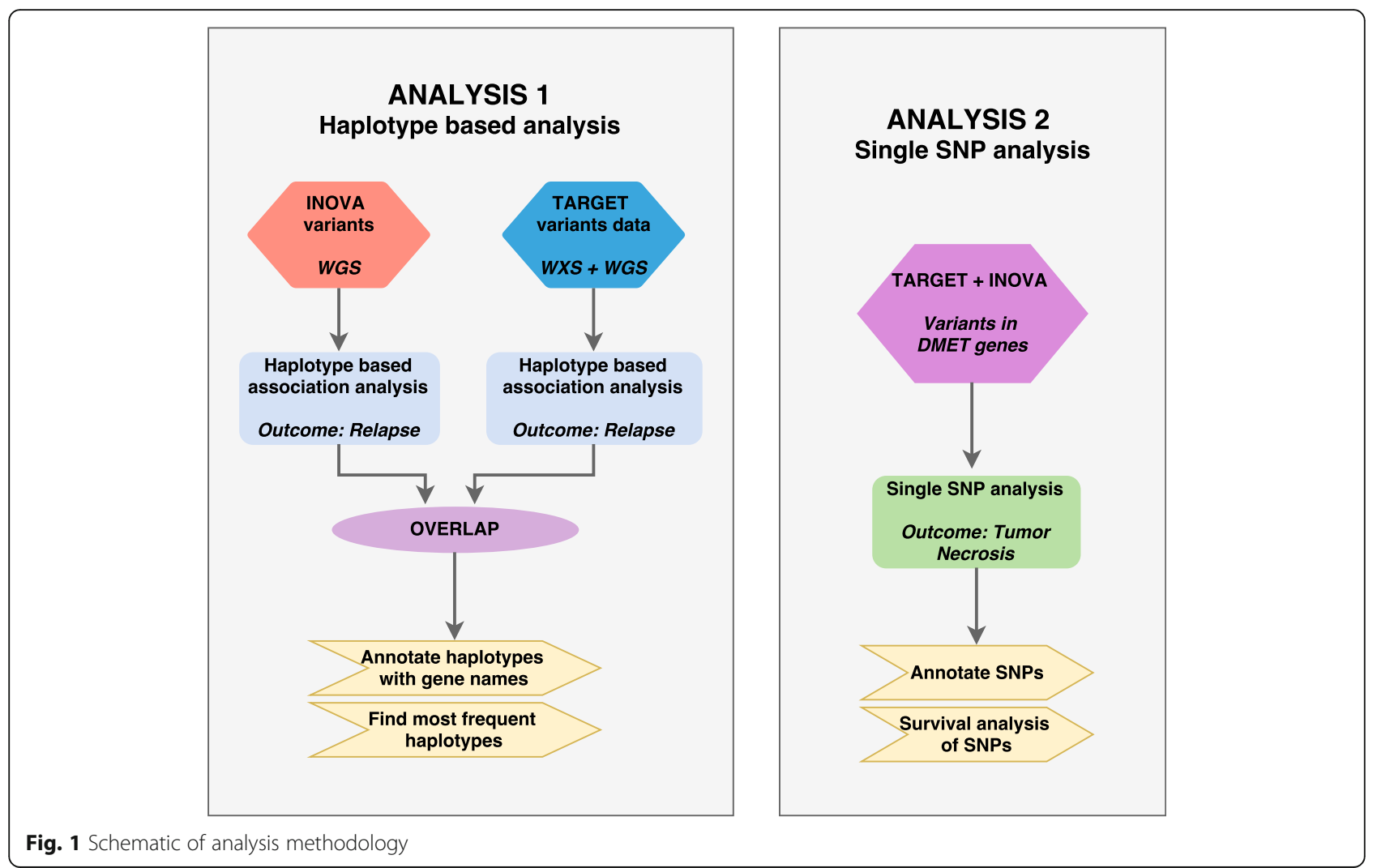

test statistic [41]. The analysis was performed in the $\mathrm{R}$ programming language. Kaplan Meier survival curves [42] were generated. Results were compared to published literature.

\section{Validation of SNPs detected using sanger sequencing}

The significant SNPs and indels obtained from our analysis of WGS data were confirmed in the lab using Sanger Sequencing technique. DNA extracted from the INOVA cohort was used for PCR amplification. Using Primer3 (http://bioinfo.ut.ee/primer3-0.4.0/), primers were designed to cover and validate the subset of variants identified by WGS. The PCR was performed using AmpliTaq Gold 360 master mix (Applied Biosystems). After Exo/SAP purification (ThermoFisher Scientific), the amplicons were sequenced by using the BigDye V.3.1 Terminator chemistry (Applied Biosystems) and separated on an ABI 3730xl genetic analyzer (Applied Biosystems). Data were evaluated using Sequencher V.5.0 software (Gene Codes).

This validation was performed on three of our analysis results: (a) variants belonging to the most frequent haplotypes in the INOVA dataset (b) variants in the form of dbSNP ids amongst the overlapping haplotypes associated with relapse and common to the two datasets (c) variants among the DMET genes significantly associated with tumor necrosis and overall survival.

\section{Results}

Mutation hotspots associated with relapse

We found a total of 2178 haplotypes significantly associated ( $p$ value $<0.05$ ) with relapse outcome in the TARGET dataset and 110,000 significant haplotypes in the INOVA dataset (more haplotypes identified in INOVA data because it was WGS data). Using chromosome location as the criteria for finding overlapping haplotypes between the two datasets, we found a total of 231 overlapping haplotypes (Additional file 3). We mapped the SNPs in these haplotypes to genes, and found 26 genes common to the TARGET and INOVA datasets associated with relapse, including AKR1D1, SLC13A2, MKI67 and PIK3R1 and others (Table 3).

We also performed enrichment analysis using Reactome database (https://reactome.org/) [43] to map these 26 genes to pathways (Table 4 ).

\section{Most frequent haplotypes amongst the overlapping hotspots}

Among the 231 overlapping haplotypes between the INOVA and TARGET datasets, we looked in detail at 
Table 3 List of 26 common genes obtained from haplotypes overlapping between INOVA and TARGET and associated with relapse outcome

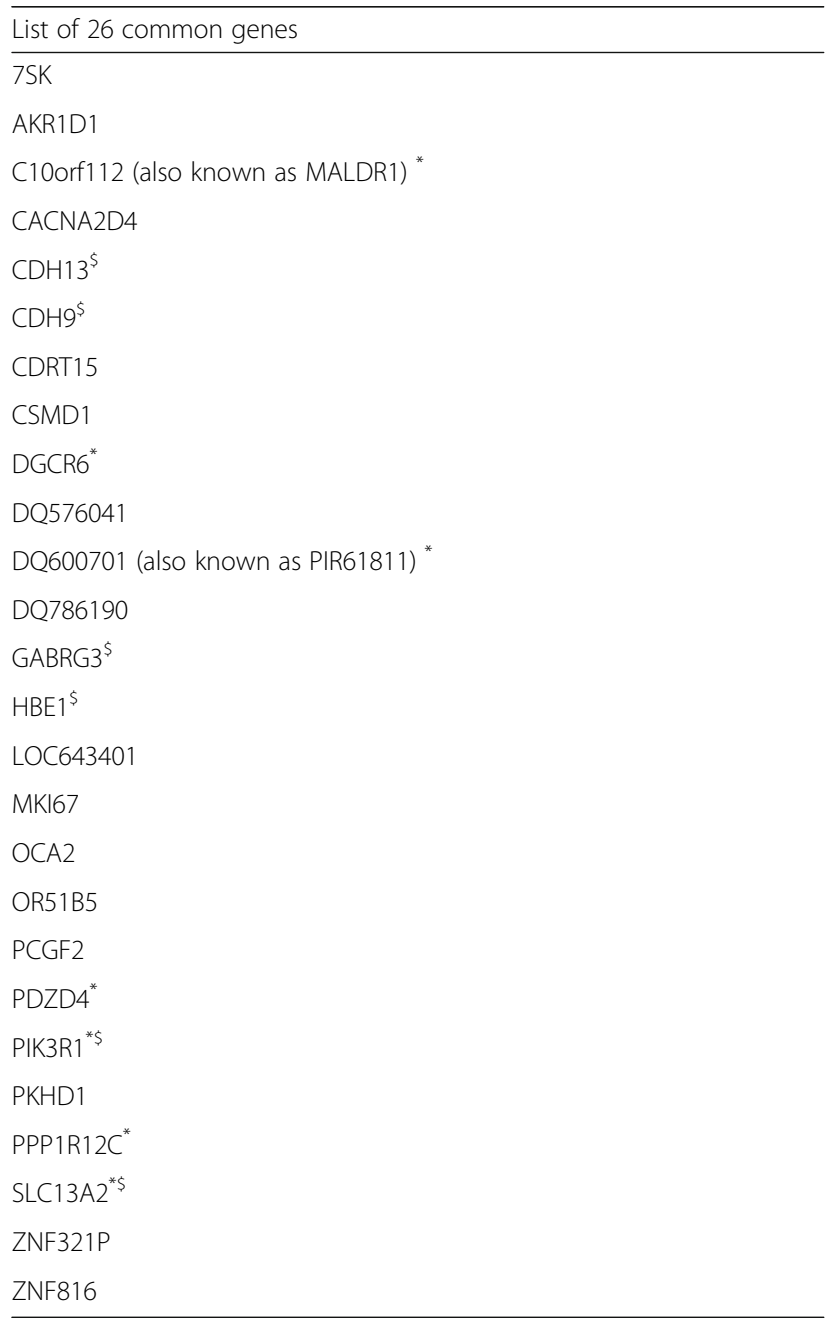

Genes marked with * indicate the most frequent haplotypes associated with relapse

Genes marked with ${ }^{\$}$ were significantly enriched in the pathway enrichment analysis (details in Table 4)

those haplotypes that have the highest sample frequency in each dataset (Table 5).

\section{Common SNPs amongst the overlapping hotspots}

Using dbSNP ids as criteria, we looked for common SNPs amongst the 231 overlapping hotspots (haplotypes) between TARGET and INOVA datasets. We found 10 dbSNP ids common to the two datasets. These include four SNPs in MKI67 (rs7071768, rs11016073, rs61738284, rs11591817), one SNP in CACNA2D4 (rs10735005), three SNPs in SLC13A2 (rs3217046, rs11568466, rs9890678), and two SNPs in PPP1R12C (rs10573756, rs34521018). These variants are important because they are part of hotspots that are significantly associated with relapse outcome. The fact that these same SNPs were found as part of hotspots in two independent datasets, and validated in the lab, indicates their potential as biomarkers for diagnostics and drug discovery.

\section{Targeted analysis of variants in DMET genes associated with tumor necrosis and survival}

We explored the association of variants in DMET genes (referred to as 'DMET variants') with tumor necrosis as outcome, and obtained a total of 281 variants with $p$ value $<0.05$ that can separate good responders and poor responders (Additional file 4). We built a predictive model using these variants. This model gave us a prediction accuracy of $87.5 \%$ when applied to the independent validation set. The confusion matrix and the summary of the model are shown in Additional file 5. We annotated these variants with SnpEff variant annotation tool [40] and grouped them into high impact, moderate impact, and modifier (non-coding regions).

A "high impact" variant is one that is predicted to have a disruptive impact in the protein, such as protein truncation, loss of function or triggering nonsense mediated decay. A "moderate impact" variant is a non-disruptive variant that might change protein effectiveness. A "low impact" variant is assumed to be harmless or unlikely to change protein behavior. "Modifier variants" are non-coding variants or variants affecting non-coding genes [40].

Out of the 281 variants significantly associated with tumor necrosis, there was one high impact variant, rs17143187, which is a splice donor variant in the ABCB5 gene. This variant is located on the boundary of exon and intron and could cause aberrant splicing that would result in a disrupted protein [44]. Sixteen moderate impact variants, 15 low impact variants, and 249 modifier variants were identified. 210 out of the 281 of these variants were located in intronic regions.

We performed survival analysis on these 281 variants, and obtained five variants as significant results ( $p$ value $<0.05)$. Thus, these 5 variants are significantly associated with both tumor necrosis and overall survival (Table 6). The Kaplan Meier survival curves for these five variants are shown in Fig. 2.

\section{Validation of SNPs detected using sanger sequencing}

The lab validation experiment was performed on three groups of analysis results: (a) 20 variants belonging to the most frequent haplotypes in the INOVA dataset (labeled as 'Group A') (b) 10 variants in the form of dbSNP ids common to the two datasets amongst the overlapping haplotypes significantly associated with relapse (labeled as 'Group B') and (c) 5 variants among the DMET genes significantly associated with tumor necrosis and overall survival (labeled as 'Group C').

Among the variants in Group A, at-least one SNP in each haplotype was successfully validated (Additional file 6). 
Table 4 Pathways enriched from the 26 genes common to TARGET and INOVA haplotypes

\begin{tabular}{|c|c|c|c|c|c|}
\hline Pathway name & $\begin{array}{l}\text { \#Entities } \\
\text { found }\end{array}$ & $\begin{array}{l}\text { \#Entities } \\
\text { total }\end{array}$ & $\begin{array}{l}\text { Entities } P \\
\text { value }\end{array}$ & $\begin{array}{l}\text { Entities } \\
\text { FDR }\end{array}$ & $\begin{array}{l}\text { Submitted entities } \\
\text { found }\end{array}$ \\
\hline Adherens junctions interactions & 2 & 35 & 0.003 & 0.228 & $\mathrm{CDH} 13 ; \mathrm{CDH} 9$ \\
\hline Cell-Cell communication & 3 & 133 & 0.003 & 0.228 & $\mathrm{CDH} 13 ; \mathrm{PIK} 3 \mathrm{R} 1 ; \mathrm{CDH} 9$ \\
\hline $\begin{array}{l}\text { Factors involved in megakaryocyte development and platelet } \\
\text { production }\end{array}$ & 3 & 179 & 0.007 & 0.228 & HBE1 \\
\hline Cell-cell junction organization & 2 & 67 & 0.009 & 0.228 & $\mathrm{CDH} 13 ; \mathrm{CDH} 9$ \\
\hline Cell junction organization & 2 & 94 & 0.017 & 0.228 & $\mathrm{CDH} 13 ; \mathrm{CDH} 9$ \\
\hline Sodium-coupled sulphate, di- and tri-carboxylate transporters & 1 & 9 & 0.019 & 0.228 & SLC13A2 \\
\hline MET activates PI3K/AKT signaling & 1 & 10 & 0.021 & 0.228 & PIK3R1 \\
\hline GP1b-IX-V activation signaling & 1 & 12 & 0.025 & 0.228 & PIK3R1 \\
\hline PI3K events in ERBB4 signaling & 1 & 15 & 0.032 & 0.228 & PIK3R1 \\
\hline GABA A receptor activation & 1 & 15 & 0.032 & 0.228 & GABRG3 \\
\hline Signaling by FGFR3 fusions in cancer & 1 & 16 & 0.034 & 0.228 & PIK3R1 \\
\hline Erythrocytes take up oxygen and release carbon dioxide & 1 & 16 & 0.034 & 0.228 & HBE1 \\
\hline Signaling by FGFR4 in disease & 1 & 18 & 0.038 & 0.228 & PIK3R1 \\
\hline PI3K events in ERBB2 signaling & 1 & 22 & 0.046 & 0.228 & PIK3R1 \\
\hline Tie2 Signaling & 1 & 22 & 0.046 & 0.228 & PIK3R1 \\
\hline
\end{tabular}

Validation of seven variants (located in intronic regions of two genes and one intergenic region) was not confirmed. Several of those that were not confirmed were located in insertion/deletion regions. All the variants in Groups B and C were successfully validated (Additional file 6).

\section{Discussion}

\section{Summary of results}

The main results are summarized in Table 7 , showing (a) the 26 genes from common haplotypes, found in both the TARGET and INOVA datasets, that are associated with relapse; and (b) The $10 \mathrm{dbSNP}$ ids among the overlapping hotspot regions common to the two datasets and (c) the genes from targeted DMET analysis associated with both tumor necrosis and overall survival. We explored these genes to see which of them are known in relation to drug response from published literature.

\section{Hotspots associated with relapse}

We performed haplotype based association analysis in the TARGET and INOVA datasets to find haplotypes associated with relapse outcome, and then looked for overlap. We found 231 haplotypes overlapping (based on chromosome location) amongst the TARGET and INOVA datasets. The SNPs in these haplotypes were mapped to genes, and 26 genes were found common between the two datasets. These 26 common genes were explored for known relationships with drug response.

Among them is AKR1D1, which has SNPs rs1872929 and rs1872930 among the hotspots in the TARGET dataset, and are in the three prime untranslated region (3' UTR) of AKR1D1. SNPs rs1872929 and rs1872930 were found as part of a haplotype and in LD with intronic SNP rs2306847 (found among the hotpots in INOVA dataset) as part of a haplotype [45]. These SNPs have been significantly associated with higher AKR1D1 mRNA expression [45]. AKR1D1 is a key genetic regulator of the P450 network, which affects drug metabolism, efficacy and adverse events in patients [45].

Genes CDH13, and CDH9 are part of the cadherin family of genes, and along with PKHD1, are part of the cell-cell adhesion biological process. This biological process is associated with a multidrug resistant phenotype, "cell adhesion-mediated drug resistance," or CAM-DR [46]. Osteoblasts express multiple cadherins [47], and cadherin mediated cell-to-cell adhesion is critical for normal human osteoblast differentiation [47]. The cadherin family of genes is associated with $\mathrm{CCN} 3$, which has been found to have prognostic value in Osteosarcoma [48]. CDH13 and CHD9 are also part of the adherens junction biological process; and adherens-dependent PI3K/AKT activation is known to induce resistance to genotoxin-induced cell death in intestinal epithelial cells [49].

Variants in gene ZNF321P (among the TARGET haplotypes) and in gene PCGF2 (among the INOVA haplotypes) are intronic and also located in active promoter regions. Similarly, intronic variants in gene PPP1R12C (among the INOVA haplotypes) are located in strong enhancer regions containing transcription factor binding sites. Mutations in such gene regulatory regions could inhibit transcription factor binding, leading to aberrant cell proliferation or drug response [50].

We hence see that some of the genes identified from our analysis are linked with drug resistance or drug 


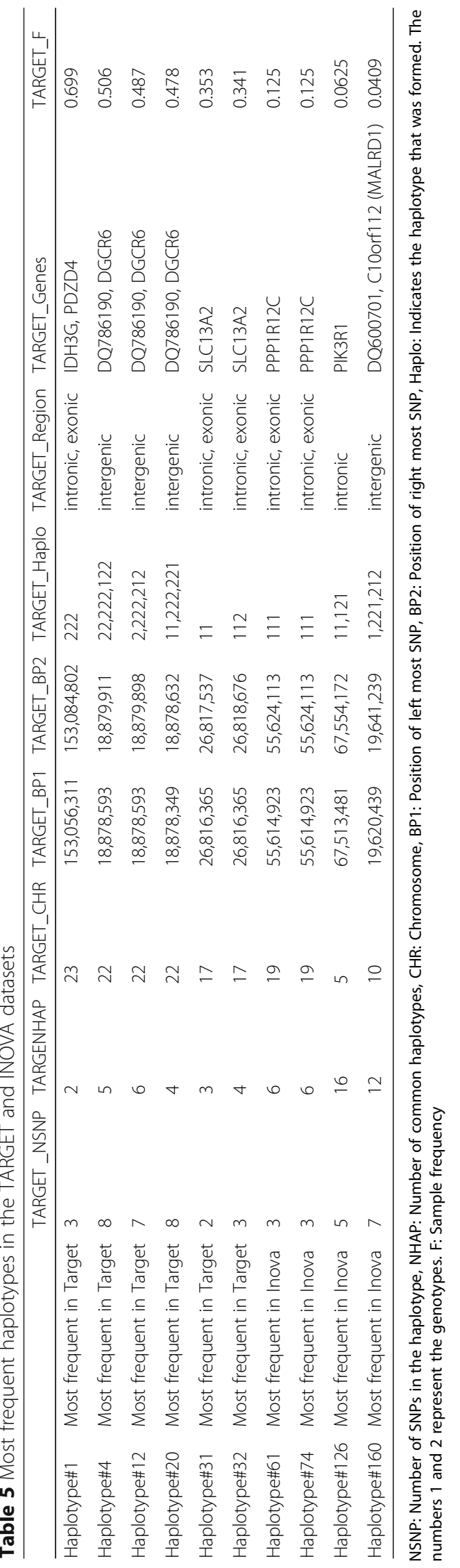




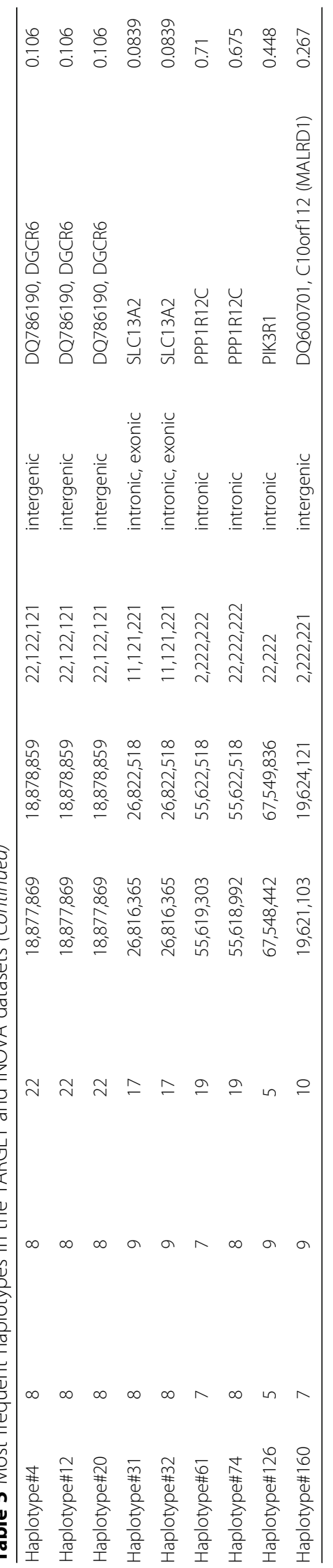




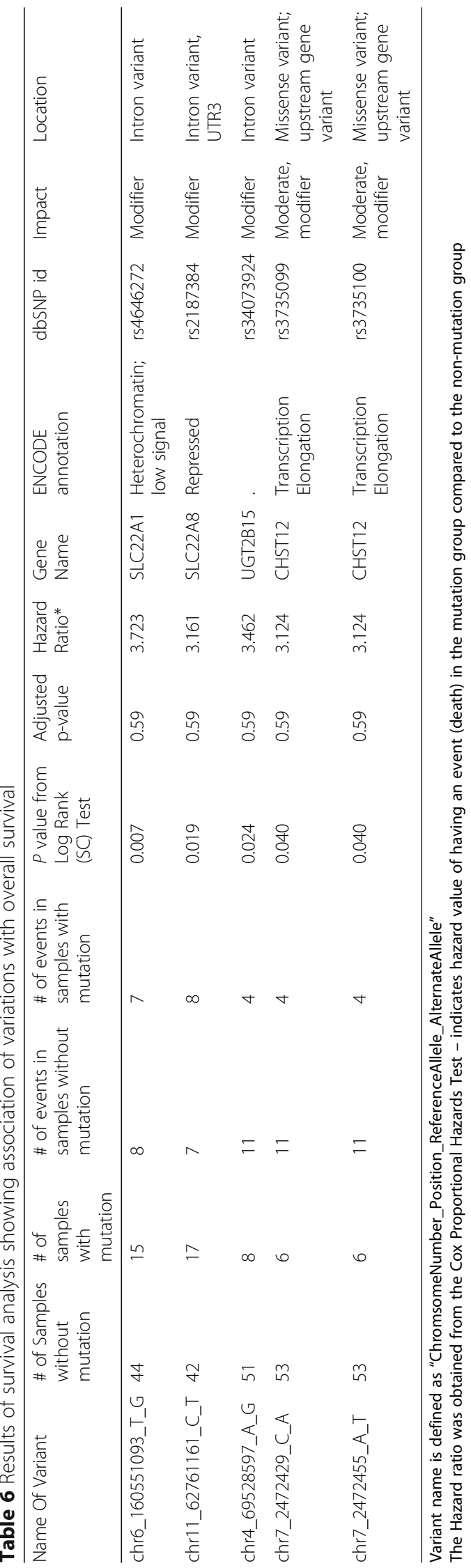




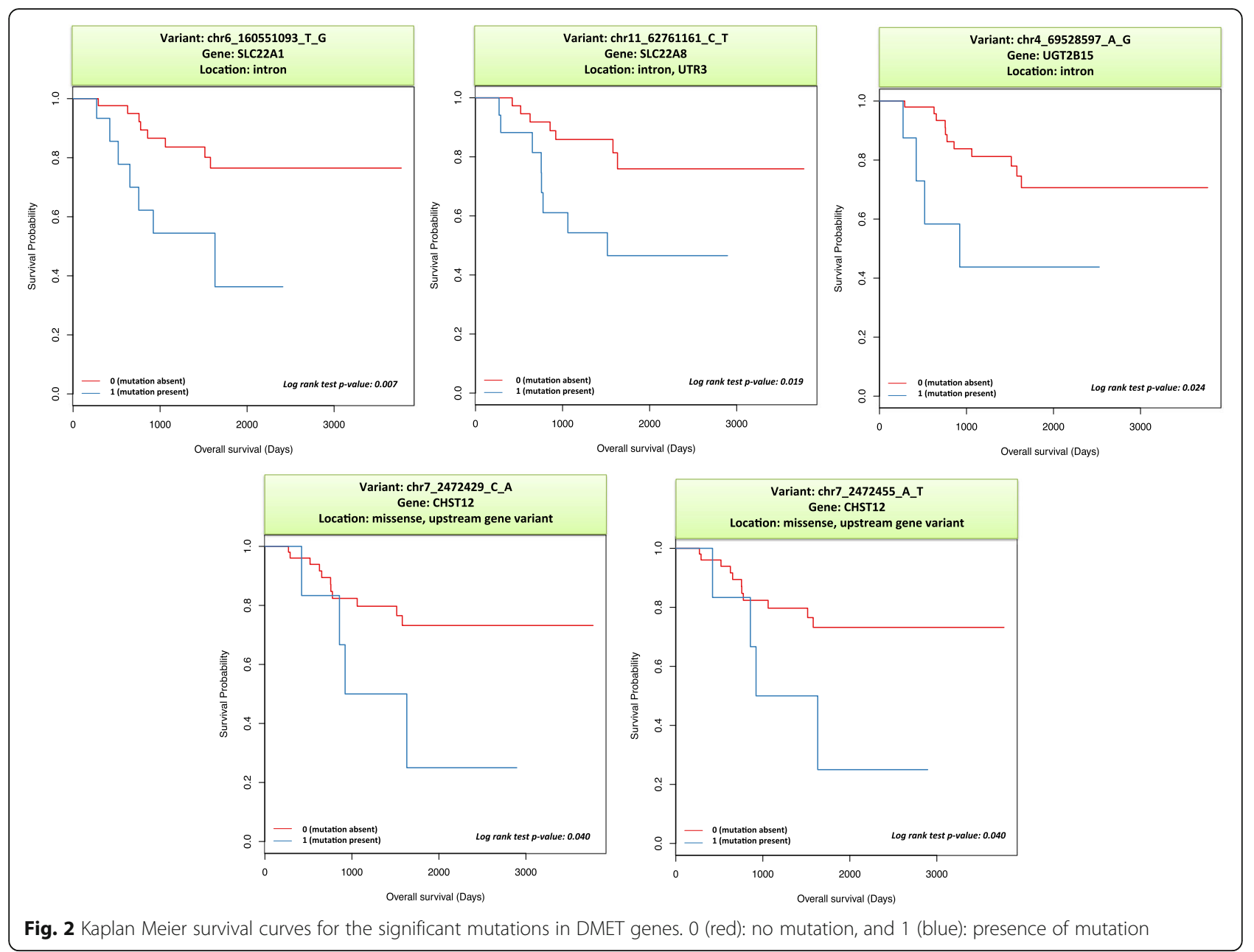

ponse; others have not been previously linked with drug response. In the genes previously linked with drug resistance or response (AKR1D1, CDH13, and CDH9), the SNPs and haplotypes found from our analyses are novel.

\section{Most frequent haplotypes}

Among the 231 common haplotypes between the INOVA and TARGET datasets, we examined the haplotypes that have the highest sample frequency (Table 5). The most frequent haplotype in the TARGET dataset span intronic and intergenic regions in or near the following genes: IDH3G, PDZD4, DQ786190, DGCR6, and SLC13A2. The most frequent haplotypes in the INOVA dataset span the region in or near the following genes: PPP1R12C, PIK3R1, DQ600701 and MALRD1.

DQ600701 (also known as PIR61811) is a Piwi-interacting RNA (piRNA), a small non-coding RNA found in clusters as regulatory elements, and control gene expression in germ cells [51-53] .Somatic cells express similar small non-coding RNAs called piRNA-like (piR-Ls or pilRNA) with similar functions as piRNAs. piRNA/pilRNAs appear to target the 3' UTR of mRNAs and potentially regulate
mRNA translation [53-55] and possibly affect drug response. For example, pilRNAs were found to play key roles in chemo resistance to cisplatin-based chemotherapy in lung squamous cell carcinoma (LSCC) [56].

Another frequent haplotype is located in the intergenic region between DQ786190 and DGCR6 [57, 58], which is located in chr 22, q11.21 region. According to Genbank, the mRNA sequence DQ786190 is involved in lineage-specific gene duplication and loss in humans [59]. According to ENCODE annotation, this intergenic region with chromosome position $18,878,593-18,878,632$ contains repetitive/copy number mutations. The INOVA dataset also contains nearby haplotypes (position $18,877,874-18,878,489$ ), which spans the intergenic region between DQ786190 and DGCR6. This region contains TATA boxes, therefore haplotypes containing multiple SNPs in this intergenic region can potentially affect transcription or gene copy number, and possibly drug response [60]. miR-145 is predicted to target this DQ786190 mRNA sequence [40]. miR-145 was found to be 5 times under expressed in the miRNA expression signature associated with canine osteosarcoma [61]. Thus, the variant 
Table 7 Summary of results obtained at the gene level

\begin{tabular}{|c|c|c|}
\hline $\begin{array}{l}\text { (a) List of } 26 \text { common genes from } \\
\text { overlapping haplotypes associated with } \\
\text { relapse }\end{array}$ & $\begin{array}{l}\text { (b) List of } 10 \text { dbSNP ids common to the two datasets } \\
\text { amongst the overlapping haplotypes associated with } \\
\text { relapse }\end{array}$ & $\begin{array}{l}\text { (c) Genes from targeted DMET analysis } \\
\text { associated with both tumor necrosis and } \\
\text { overall survival }\end{array}$ \\
\hline $7 S K$ & rs7071768 (MKI67) & SLC22A8 \\
\hline AKR1D1 & rs11016073 (MKI67) & SLC22A1 \\
\hline CACNA2D4 & rs61738284 (MKI67) & UGT2B15 \\
\hline $\mathrm{CDH} 13$ & rs11591817 (MKI67) & CHST12 \\
\hline $\mathrm{CDH} 9$ & rs10735005 (CACNA2D4) & \\
\hline CDRT15 & rs3217046 (SLC13A2) & \\
\hline CSMD1 & rs11568466 (SLC13A2) & \\
\hline DGCR6* & rs9890678 (SLC13A2) & \\
\hline DQ576041 & rs10573756 (PPP1R12C) & \\
\hline DQ600701 (also known as PIR61811) * & rs34521018 (PPP1R12C) & \\
\hline \multicolumn{3}{|l|}{ DQ786190 } \\
\hline \multicolumn{3}{|l|}{ GABRG3 } \\
\hline \multicolumn{3}{|l|}{ HBE1 } \\
\hline \multicolumn{3}{|l|}{ LOC643401 } \\
\hline \multicolumn{3}{|l|}{ MALDR1 (also known as C10orf112) * } \\
\hline \multicolumn{3}{|l|}{ MKI67 } \\
\hline \multicolumn{3}{|l|}{ OCA2 } \\
\hline \multicolumn{3}{|l|}{ OR51B5 } \\
\hline \multicolumn{3}{|l|}{ PCGF2 } \\
\hline \multicolumn{3}{|l|}{ PDZD4 * } \\
\hline \multicolumn{3}{|l|}{$\mathrm{PIK} 3 \mathrm{R} 1$ * } \\
\hline \multicolumn{3}{|l|}{ PKHD1 } \\
\hline \multicolumn{3}{|l|}{ PPP1R12C* } \\
\hline \multicolumn{3}{|l|}{$\mathrm{SLC13A2*}$} \\
\hline \multicolumn{3}{|l|}{ ZNF321P } \\
\hline ZNF816 & & \\
\hline
\end{tabular}

Genes marked with * indicate the most frequent haplotypes associated with relapse

haplotype could affect drug response through decreased miRNA binding [62].

SLC13A2 is the only Drug Metabolizing Enzyme and Transporter (DMET) gene that has significant haplotypes present in the TARGET and the INOVA dataset. This gene is known to play an important role in transporter activity [63]. SLC13A2 was down regulated along with miR-9 overexpression in malignant murine mastocytoma cell lines, and in primary canine osteosarcoma (OSA) tumors and cell lines [64]. Another gene in the same solute carrier family is SLC19A1, which is a folate carrier. Reduced folate carrier function has been associated with impaired methotrexate transport in osteosarcoma tumors $[65,66]$. Polymorphisms in SLC19A1 have been associated with response to methotrexate treatment in pediatric osteosarcoma $[67,68]$. In recent years, these SLC transporters have been recognized as having the potential to transport and deliver anticancer chemotherapeutic agents, and are being studied as drug targets in cancer $[69,70]$.

Another gene in the list is PIK3R1, which encodes regulatory subunits of PI3-kinase [71]. The PI3K pathway is frequently activated in cancer due to genetic (e.g., amplifications, mutations, deletions) and epigenetic (e.g., methylation, regulation by non-coding RNAs) aberrations targeting its key components, and may affect response to specific therapeutic agents [72]. Hotspots in exonic regions of PIK3R1 (residue M582_splice, N564, G376, R348, K567) have been found in tumor samples of various cancers (http://cancerhotspots.org/) [73]. In Zhao et al., the authors found that up-regulation of long non-coding RNA promoted osteosarcoma proliferation and migration through the regulation of PIK3IP1, another protein in the PI3K pathway [74]. 


\section{Common SNPs amongst the overlapping hotspots}

The 4 SNPs in the MKI67 gene rs7071768, rs11016073, rs61738284 and rs11591817 are present in the hotspots in the TARGET and INOVA datasets. All these SNPs are non-synonymous and are expected to affect protein function. According to ENCODE annotation, these SNPs are located in regions of transcription elongation, which can have broad effects on gene expression. Mutations in these regulatory regions have been linked with disease mechanisms [75] and possibly modified drug response. The gene MKI67 is often used as a surrogate biomarker to score the aggressiveness of the tumor, and expression of this gene has been used as a predictor of response to chemotherapy in breast cancer patients [76, 77].

\section{Targeted analysis of variants in DMET genes associated with tumor necrosis and overall survival}

Among the 281 DMET variants that were significantly associated with tumor necrosis, was gene ABCG2. This gene is part of the Methotrexate metabolic pathway (MTX pathway), and mutations in this gene have been implicated in MTX efficacy and toxicity. This is gene is also linked with breast cancer treatment resistance [78].

The only high impact variant was rs17143187, which is a splicing and intron variant in the ABCB5 gene. Alternative splicing and ABCB5 SNPs are known to affect drug response [79-81]. This mutation is predicted to be a deleterious mutation based on FATHMM prediction algorithm [82].

Among the 281 variants that were significantly associated with tumor necrosis, 5 variants were significantly associated with overall survival as well. All these 5 variants have a hazard ratio of 3 , meaning that at any particular time, three times as many patients in the mutation group are experiencing an event (death) compared to patients in the non-mutation group.

A total of 210 of the 281 significant variants were located in intronic regions, which is consistent with known literature. Luizon and Ahituv reviewed all published pharmacogenomics genome wide association studies (GWAS) and found that $96.4 \%$ of the SNPs reside in noncoding regions [50]. Intronic regions typically harbor microRNAs and long non-coding RNA, other regulatory elements, epigenetic elements and structural variants $[83,84]$. These intronic regions are sites of intron retention, in which the introns are not spliced out, but are retained. Recent studies have shown that intron retention affects regulation of gene expression and RNA translation $[85,86]$.

Variants in introns can affect drug response by altering the gene expression [83, 87-91]. In recent years, noncoding RNA are being researched as potential drug targets since they affect gene expression and disease progression [92]. Enhancers have been identified as potential biomarkers for early cancer detection, and targets for cancer therapy [93]. Hotspot regions are being researched for their potential as targets for diagnosis and drug development [73, 94].

Hence, some of the significant variants obtained from our analyses are supported by reports in the literature and serve as in-silico validation of our results, while other variants are novel, and offer additional value for exploration of new and novel drug therapies.

\section{Limitations}

Although the major findings were statistically significant and confirmed by Sanger sequencing, the sample size of the INOVA cohort was relatively low. The relevance of these findings with respect to drug response needs to be validated in a larger independent cohort of patients before applying in clinics. As next steps, we plan to explore the application of the significant haplotypes and single SNPs discovered, in a larger scale study to build a predictive signature of genomic variants associated with treatment outcome.

A recent publication on pan-can analyses of pediatric cancers by the TARGET group [24] published in March 2018, showed that that the mutation rate in osteosarcomas is much higher in the non-coding regions $(0.79$ per $\mathrm{Mb}$ ) than in coding regions $(0.53$ per $\mathrm{Mb})$. Being a whole-genome sequencing dataset, the INOVA cohort lends itself as an independent dataset to be studied in-depth in future research projects. Hence there is much promise in the analysis and exploration of the whole genome for future research work in OS.

\section{Conclusion}

Most publications that study drug response in Osteosarcoma focus on the exonic regions. However, most of the studies of OS have not been focusing on whole genome analysis with regard to treatment response. We hypothesized that genetic variation of the host may account for the wide variation seen in the response and toxicity related to chemotherapeutic agents. Our analysis approach was different from other studies that search for individual SNPs to confer significance. Using groups of SNPs for analyses has increased power in finding associations as well as increased robustness in statistical testing.

From our analyses, we found a list of intronic and intergenic hotspot regions common to both the TARGET and INOVA datasets that are significantly associated with outcome, providing insights into drug response mechanisms. Some of the genes with variants found in this study are linked with drug response at the pathway level (gene/pathway/biological processes level). Our results include variants in genes not previously linked with drug response, as well as novel SNPs and 
haplotypes in genes known to be linked with drug resistance. The targeted single SNP analysis of the DMET genes found variants significantly associated with both tumor necrosis outcome and survival.

We were able to validate the majority of the variants in our results using Sanger sequencing at the individual patient level. Identification and validation of such genetic markers that predict drug treatment response provide the basis for prospective evaluation of these candidate markers, and for future upfront treatment design based on individual genomic profiles.

\section{Additional files}

Additional file 1: The steps, file formats and tools in the genomic data processing. (DOCX $148 \mathrm{~kb}$ )

Additional file 2: Detailed processing steps of Analysis 2 including the block diagram, filtering steps, PCA plot, equations of the generalized linear models. (DOCX $1860 \mathrm{~kb}$ )

Additional file 3: Details of the 231 haplotypes overlapping between the two datasets. (XLSX $83 \mathrm{~kb}$ )

Additional file 4: Details of the 281 variants significantly associated with tumor necrosis. (XLSX $114 \mathrm{~kb}$ )

Additional file 5: The confusion matrix and the summary of the generalized linear models. (DOCX $71 \mathrm{~kb}$ )

Additional file 6: Details of the Sanger Sequencing validation. (XLSX $88 \mathrm{~kb}$ )

\section{Abbreviations}

3' UTR: Three prime untranslated region; ADME: Absorption, metabolism, distribution, and elimination; ANOVA: Analysis of variance; CAM-DR: Cell adhesion-mediated drug resistance; COG: Children's Oncology Group; DMET: Drug Metabolizing Enzymes and Transporter; FDR: False discovery rate; GLMs: Generalized linear models; GWAS: Genome wide association studies; haploblock: Haplotype block; LD: Linkage disequilibrium; MTX pathway: Methotrexate metabolic pathway; OS: Osteosarcoma; PCA: Principal component analysis; piR-Ls or pilRNA: piRNA-like; piRNA: Piwi-interacting RNA; SNPs: Single nucleotide polymorphisms; WGS: Whole genome sequencing

\section{Acknowledgements}

The results published here are in part based upon data generated by the Therapeutically Applicable Research to Generate Effective Treatments (TARGET) initiative, phs000218, managed by the NCl. The data used for this analysis are available via dbGAP at phs000468.v14.p6 [25]. Information about TARGET can be found at http://ocg.cancer.gov/programs/target.

The authors would also like to thank Keary Jane't for her compassion and commitment to this project; Sakthi Madhappan and Miguel Cruz for setting up and managing the Amazon cloud instance.

\section{Funding}

The principal investigators were the recipients of the 2014 Hyundai Scholar's Hope Award, which has funded this work. This work was also funded by the P30 CA51008 Georgetown Lombardi Cancer Center support grant. The funding agencies reviewed the original research proposal but were not involved in designing the study, collection, analysis or interpretation of data or writing of the manuscript.

\section{Availability of data and materials}

The genome sequencing data for the Osteosarcoma TARGET cohort was obtained and available to the public via the dbGAP repository at phs000468.v14.p6 [25]. The whole genome sequencing data from the INOVA cohort could be made available through reasonable request and with permission of Inova Pls after the manuscript has been published.

\section{Authors' contributions}

SS, JD and $\mathrm{MH}$ designed the study. $\mathrm{KB}, \mathrm{MH}$ and $\mathrm{YG}$ created the analysis plan and performed the analysis. KB and YG wrote the paper. EY, SS, MH and SM reviewed and edited the paper. RI performed the whole genome sequencing. RI and TV performed the lab validation. All other authors provided editorial comments. All authors have read and approved the manuscript.

\section{Ethics approval and consent to participate}

The study was approved by the Institutional Review Board of the Inova Fairfax Hospital. Written informed consent was obtained from participants who were greater than 18 years of age. For participants under 18 years of age, written informed consent was obtained from the parents.

\section{Consent for publication}

$\mathrm{N} / \mathrm{A}$

\section{Competing interests}

None of the authors have any competing interests.

\section{Publisher's Note}

Springer Nature remains neutral with regard to jurisdictional claims in published maps and institutional affiliations.

\section{Author details}

${ }^{1}$ Innovation Center for Biomedical Informatics, Georgetown University Medical Center, Washington DC, USA. ${ }^{2}$ Inova Translational Medicine Institute, Fairfax, VA, USA. ${ }^{3}$ Inova Children's Hospital, Falls Church, VA, USA. ${ }^{4}$ Center for Cancer and Blood Disorders of Northern Virginia, Pediatric Specialists of Virginia, Falls Church, VA, USA. ${ }^{5}$ George Washington University School of Medicine, Washington DC, USA. 'Virginia Commonwealth University School of Medicine, Inova Campus, Falls Church, VA, USA.

Received: 10 November 2017 Accepted: 14 March 2019

Published online: 16 April 2019

\section{References}

1. Meyers PA, Gorlick R. Osteosarcoma. Pediatr Clin N Am. 1997;44(4):973-89.

2. Link MP, Goorin AM, Miser AW, Green AA, Pratt CB, Belasco JB, Pritchard J, Malpas JS, Baker AR, Kirkpatrick JA, et al. The effect of adjuvant chemotherapy on relapse-free survival in patients with osteosarcoma of the extremity. N Engl J Med. 1986;314(25):1600-6.

3. Meyers PA, Heller G, Healey J, Huvos A, Lane J, Marcove R, Applewhite A, Vlamis $V$, Rosen G. Chemotherapy for nonmetastatic osteogenic sarcoma: the memorial Sloan-Kettering experience. J Clin Oncol. 1992;10(1):5-15.

4. Provisor AJ, Ettinger LJ, Nachman JB, Krailo MD, Makley JT, Yunis EJ, Huvos AG, Betcher DL, Baum ES, Kisker CT, et al. Treatment of nonmetastatic osteosarcoma of the extremity with preoperative and postoperative chemotherapy: a report from the Children's Cancer group. J Clin Oncol. 1997;15(1):76-84.

5. Bielack SS, Kempf-Bielack B, Delling G, Exner GU, Flege S, Helmke K, Kotz R, Salzer-Kuntschik M, Werner M, Winkelmann W, et al. Prognostic factors in high-grade osteosarcoma of the extremities or trunk: an analysis of 1,702 patients treated on neoadjuvant cooperative osteosarcoma study group protocols. J Clin Oncol. 2002;20(3):776-90.

6. Whelan JS, Jinks RC, McTiernan A, Sydes MR, Hook JM, Trani L, Uscinska B, Bramwell V, Lewis IJ, Nooij MA, et al. Survival from high-grade localised extremity osteosarcoma: combined results and prognostic factors from three European osteosarcoma intergroup randomised controlled trials. Ann Oncol. 2012;23(6):1607-16.

7. Meyers PA, Schwartz CL, Krailo MD, Healey JH, Bernstein ML, Betcher D, Ferguson WS, Gebhardt MC, Goorin AM, Harris M, et al. Osteosarcoma: the addition of muramyl tripeptide to chemotherapy improves overall survival-a report from the Children's oncology group. J Clin Oncol. 2008;26(4):633-8.

8. Kung FH, Pratt CB, Vega RA, Jaffe N, Strother D, Schwenn M, Nitschke R, Homans AC, Holbrook CT, Golembe B, et al. Ifosfamide/etoposide combination in the treatment of recurrent malignant solid tumors of childhood. A pediatric oncology group phase II study. Cancer. 1993;71(5):1898-903.

9. Miser JS, Kinsella TJ, Triche TJ, Tsokos M, Jarosinski P, Forquer R, Wesley R, Magrath I. Ifosfamide with mesna uroprotection and etoposide: an effective 
regimen in the treatment of recurrent sarcomas and other tumors of children and young adults. J Clin Oncol. 1987;5(8):1191-8.

10. Fuchs N, Bielack SS, Epler D, Bieling P, Delling G, Korholz D, Graf N, Heise U, Jurgens $H$, Kotz R, et al. Long-term results of the co-operative GermanAustrian-Swiss osteosarcoma study group's protocol COSS-86 of intensive multidrug chemotherapy and surgery for osteosarcoma of the limbs. Ann Oncol. 1998;9(8):893-9.

11. International HapMap C. A haplotype map of the human genome. Nature. 2005;437(7063):1299-320.

12. Deeken J. The Affymetrix DMET platform and pharmacogenetics in drug development. Curr Opin Mol Ther. 2009;11(3):260-8.

13. Iyer L, Das S, Janisch L, Wen M, Ramirez J, Karrison T, Fleming GF, Vokes EE, Schilsky RL, Ratain MJ. UGT1A1*28 polymorphism as a determinant of irinotecan disposition and toxicity. Pharmacogenomics J. 2002;2(1):43-7.

14. Evans WE, Hon YY, Bomgaars L, Coutre S, Holdsworth M, Janco R, Kalwinsky D, Keller F, Khatib Z, Margolin J, et al. Preponderance of thiopurine Smethyltransferase deficiency and heterozygosity among patients intolerant to mercaptopurine or azathioprine. J Clin Oncol. 2001;19(8):2293-301.

15. Pullarkat ST, Stoehlmacher J, Ghaderi V, Xiong YP, Ingles SA, Sherrod A, Warren R, Tsao-Wei D, Groshen S, Lenz HJ. Thymidylate synthase gene polymorphism determines response and toxicity of 5-FU chemotherapy. Pharmacogenomics J. 2001;1(1):65-70.

16. Dehal SS, Kupfer D. CYP2D6 catalyzes tamoxifen 4-hydroxylation in human liver. Cancer Res. 1997;57(16):3402-6.

17. Deeken JF, Figg WD, Bates SE, Sparreboom A. Toward individualized treatment: prediction of anticancer drug disposition and toxicity with pharmacogenetics. Anti-Cancer Drugs. 2007;18(2):111-26.

18. Hattinger CM, Tavanti E, Fanelli M, Vella S, Picci P, Serra M. Pharmacogenomics of genes involved in antifolate drug response and toxicity in osteosarcoma. Expert Opin Drug Metab Toxicol. 2017;13(3):245-57.

19. Horton I, Lin Y, Reed G, Wiepert M, Hart S. Empowering Mayo Clinic Individualized Medicine with Genomic Data Warehousing. J Pers Med. 2017; 7(3):E7. https://doi.org/10.3390/jpm7030007.

20. Harris M, Bhuvaneshwar K, Natarajan T, Sheahan L, Wang D, Tadesse MG, Shoulson I, Filice R, Steadman K, Pishvaian MJ, et al. Pharmacogenomic characterization of gemcitabine response--a framework for data integration to enable personalized medicine. Pharmacogenet Genomics. 2014;24(2):81-93.

21. Horak P, Frohling S, Glimm H. Integrating next-generation sequencing into clinical oncology: strategies, promises and pitfalls. ESMO Open. 2016;1(5): e000094.

22. FASTQ format. https://en.wikipedia.org/wiki/FASTQ_format. Accessed 11 Aug 2017.

23. Osteosarcoma [https://ocg.cancer.gov/programs/target/projects/ osteosarcoma] Last Accessed 11 Aug 2017.

24. Ma X, Liu Y, Liu Y, Alexandrov LB, Edmonson MN, Gawad C, Zhou X, Li Y, Rusch MC, Easton J, et al. Pan-cancer genome and transcriptome analyses of 1,699 paediatric leukaemias and solid tumours. Nature. 2018;555(7696):371-6.

25. TARGET: Osteosarcoma (OS). https://www.ncbi.n/m.nih.gov/projects/gap/cgibin/study.cgi?study_id=phs000468.v14.p6. Accessed 11 Aug 2017.

26. Sequence Alignment Map. https://samtools.github.io/hts-specs/SAMv1.pdf. Accessed 11 Aug 2017.

27. Sickle: A sliding-window, adaptive, quality-based trimming tool for FastQ files [https://github.com/najoshi/sickle] Last Accessed 26 June 2017.

28. Langmead B, Salzberg SL. Fast gapped-read alignment with bowtie 2. Nat Methods. 2012;9(4):357-9.

29. Li H, Handsaker B, Wysoker A, Fennell T, Ruan J, Homer N, Marth G, Abecasis G, Durbin R. Genome project data processing S: the sequence alignment/ map format and SAMtools. Bioinformatics. 2009;25(16):2078-9.

30. Picard. http://broadinstitute.github.io/picard. Accessed 26 June 2017.

31. McKenna A, Hanna M, Banks E, Sivachenko A, Cibulskis K, Kernytsky A, Garimella K, Altshuler D, Gabriel S, Daly M, et al. The genome analysis toolkit: a MapReduce framework for analyzing next-generation DNA sequencing data. Genome Res. 2010;20(9):1297-303.

32. Davis AM, Bell RS, Goodwin PJ. Prognostic factors in osteosarcoma: a critical review. J Clin Oncol. 1994;12(2):423-31.

33. Hey J. What's so hot about recombination hotspots? PLoS Biol. 2004;2(6):e190.

34. Haplotype. https://en.wikipedia.org/wiki/Haplotype. Accessed 26 June 2017.

35. Tan Q, Christiansen L, Bathum L, Zhao JH, Yashin Al, Vaupel JW, Christensen $\mathrm{K}$, Kruse TA. Estimating haplotype relative risks on human survival in population-based association studies. Hum Hered. 2005;59(2):88-97.
36. Purcell S, Neale B, Todd-Brown K, Thomas L, Ferreira MA, Bender D, Maller J, Sklar P, de Bakker PI, Daly MJ, et al. PLINK: a tool set for whole-genome association and population-based linkage analyses. Am J Hum Genet. 2007;81(3):559-75.

37. Chang CC, Chow CC, Tellier LC, Vattikuti S, Purcell SM, Lee JJ. Secondgeneration PLINK: rising to the challenge of larger and richer datasets. Gigascience. 2015;4:7.

38. Caret. https://cran.r-project.org/web/packages/caret/caret.pdf. Accessed 11 Aug 2017.

39. Benjamini $Y$, Hochberg $Y$. Controlling the false discovery rate - a practical and powerful approach to multiple testing. J Roy Stat Soc B Met. 1995;57(1):289-300.

40. Cingolani P, Platts A, Wang le L, Coon M, Nguyen T, Wang L, Land SJ, Lu X, Ruden DM. A program for annotating and predicting the effects of single nucleotide polymorphisms, SnpEff: SNPs in the genome of Drosophila melanogaster strain w1118; iso-2; iso-3. Fly (Austin). 2012;6(2):80-92.

41. Survival: Survival Analysis. https://cran.r-project.org/package=survival. Accessed 23 June 2017.

42. Goel MK, Khanna P, Kishore J. Understanding survival analysis: Kaplan-Meier estimate. Int J Ayurveda Res. 2010;1(4):274-8.

43. Fabregat A, Sidiropoulos K, Garapati P, Gillespie M, Hausmann K, Haw R, Jassal B, Jupe S, Korninger F, McKay S, et al. The Reactome pathway knowledgebase. Nucleic Acids Res. 2016;44(D1):D481-7.

44. Understanding Cancer Genomics. http://www.ubooks.pub/Books/ON/B0/ E10R1010/TOC.html. Accessed 29 Nov 2018.

45. Chaudhry AS, Thirumaran RK, Yasuda K, Yang X, Fan Y, Strom SC, Schuetz EG. Genetic variation in aldo-keto reductase 1D1 (AKR1D1) affects the expression and activity of multiple cytochrome P450s. Drug Metab Dispos. 2013;41(8):1538-47.

46. Cell adhesion. https://en.wikipedia.org/wiki/Cell_adhesion. Accessed 26 June 2017.

47. Cheng SL, Lecanda F, Davidson MK, Warlow PM, Zhang SF, Zhang L, Suzuki $S$, St John T, Civitelli R. Human osteoblasts express a repertoire of cadherins, which are critical for BMP-2-induced osteogenic differentiation. J Bone Miner Res. 1998;13(4):633-44.

48. Perbal B, Zuntini M, Zambelli D, Serra M, Sciandra M, Cantiani L, Lucarelli E, Picci P, Scotlandi K. Prognostic value of CCN3 in osteosarcoma. Clin Cancer Res. 2008;14(3):701-9.

49. Chae B, Yang KM, Kim TI, Kim WH. Adherens junction-dependent PI3K/Akt activation induces resistance to genotoxin-induced cell death in differentiated intestinal epithelial cells. Biochem Biophys Res Commun. 2009;378(4):738-43.

50. Luizon MR, Ahituv N. Uncovering drug-responsive regulatory elements. Pharmacogenomics. 2015;16(16):1829-41.

51. Piwi-interacting RNA (piRNA). https://en.wikipedia.org/wiki/Piwi-interacting RNA. Accessed 12 June 2017.

52. PIR61811. http://www.genecards.org/cgi-bin/carddisp.pl?gene=PIR61811. Accessed 12 June 2017.

53. Ng KW, Anderson C, Marshall EA, Minatel BC, Enfield KS, Saprunoff HL, Lam WL, Martinez VD. Piwi-interacting RNAs in cancer: emerging functions and clinical utility. Mol Cancer. 2016;15:5.

54. Ortogero N, Schuster AS, Oliver DK, Riordan CR, Hong AS, Hennig GW, Luong D, Bao J, Bhetwal BP, Ro S, et al. A novel class of somatic small RNAs similar to germ cell pachytene PIWI-interacting small RNAs. J Biol Chem. 2014;289(47):32824-34.

55. Mei $Y$, Wang $Y$, Kumari $P$, Shetty AC, Clark D, Gable T, Mackerell AD, Ma MZ, Weber DJ, Yang AJ, et al. A piRNA-like small RNA interacts with and modulates p-ERM proteins in human somatic cells. Nat Commun. 2015;6:7316

56. Wang Y, Gable T, Ma MZ, Clark D, Zhao J, Zhang Y, Liu W, Mao L, Mei Y. A piRNA-like small RNA induces Chemoresistance to cisplatin-based therapy by inhibiting apoptosis in lung squamous cell carcinoma. Mol Ther Nucleic Acids. 2017;6:269-78.

57. DGCR6. http://www.genecards.org/cgi-bin/carddisp.pl?gene=DGCR6. Accessed 30 June 2017.

58. DIGEORGE SYNDROME CRITICAL REGION GENE 6; DGCR6. https://www. omim.org/entry/601279. Accessed 30 June 2017.

59. GenBank: DQ786190.1. https://www.ncbi.nlm.nih.gov/nuccore/DQ786190. Accessed 30 June 2017.

60. Savinkova LK, Ponomarenko MP, Ponomarenko PM, Drachkova IA, Lysova MV, Arshinova TV, Kolchanov NA. TATA box polymorphisms in human gene 
promoters and associated hereditary pathologies. Biochemistry (Mosc). 2009;74(2):117-29.

61. Fenger JM, Roberts RD, Iwenofu OH, Bear MD, Zhang X, Couto Jl, Modiano JF, Kisseberth WC, London CA. MiR-9 is overexpressed in spontaneous canine osteosarcoma and promotes a metastatic phenotype including invasion and migration in osteoblasts and osteosarcoma cell lines. BMC Cancer. 2016;16(1):784.

62. Sarkar FH, Li Y, Wang Z, Kong D, Ali S. Implication of microRNAs in drug resistance for designing novel cancer therapy. Drug Resist Updat. 2010;13(3):57-66.

63. SLC13A2 Gene. http://www.genecards.org/cgi-bin/carddisp.pl?gene= SLC13A2. Accessed 9 June 2017.

64. Fenger JM. Investigating the biological and molecular consequences of MiR-9 dysregulation in canine mast cell tumors and osteosarcoma. The Ohio State University; 2015. http://rave.ohiolink.edu/etdc/view?acc_num= osu1429761923.

65. Sowers R, Wenzel BD, Richardson C, Meyers PA, Healey JH, Levy AS, Gorlick R. Impairment of methotrexate transport is common in osteosarcoma tumor samples. Sarcoma. 2011;2011:834170.

66. Pletscher-Frankild S, Palleja A, Tsafou K, Binder JX, Jensen L. DISEASES: text mining and data integration of disease-gene associations. Methods. 2015;74:83-9.

67. Park JA, Shin HY. Influence of genetic polymorphisms in the folate pathway on toxicity after high-dose methotrexate treatment in pediatric osteosarcoma. Blood Res. 2016;51(1):50-7.

68. Park JA, Shin HY. ATIC gene polymorphism and histologic response to chemotherapy in pediatric osteosarcoma. J Pediatr Hematol Oncol. 2017; 39(5):e270-4.

69. Lin L, Yee SW, Kim RB, Giacomini KM. SLC transporters as therapeutic targets: emerging opportunities. Nat Rev Drug Discov. 2015;14(8):543-60.

70. Li Q, Shu Y. Role of solute carriers in response to anticancer drugs. Mol Cell Ther. 2014;2:15.

71. PIK3R1 [http://www.genecards.org/cgi-bin/carddisp.pl?gene=PIK3R1] Last Accessed 9 June 2017

72. Weigelt B, Downward J. Genomic determinants of PI3K pathway inhibitor response in Cancer. Front Oncol. 2012;2:109.

73. Chang MT, Asthana S, Gao SP, Lee BH, Chapman JS, Kandoth C, Gao J, Socci $N D$, Solit $D B$, Olshen $A B$, et al. Identifying recurrent mutations in cancer reveals widespread lineage diversity and mutational specificity. Nat Biotechnol. 2016;34(2):155-63.

74. Zhao J, Cheng L. Long non-coding RNA CCAT1/miR-148a axis promotes osteosarcoma proliferation and migration through regulating PIK3IP1. Acta Biochim Biophys Sin Shanghai. 2017:49(6):503-12.

75. Lee TI, Young RA. Transcriptional regulation and its misregulation in disease. Cell. 2013;152(6):1237-51

76. Fasching PA, Heusinger K, Haeberle L, Niklos M, Hein A, Bayer CM, Rauh C, Schulz-Wendtland R, Bani MR, Schrauder M, et al. Ki67, chemotherapy response, and prognosis in breast cancer patients receiving neoadjuvant treatment. BMC Cancer. 2011;11:486.

77. Kim Kl, Lee KH, Kim TR, Chun YS, Lee TH, Park HK. Ki-67 as a predictor of response to neoadjuvant chemotherapy in breast cancer patients. J Breast Cancer. 2014;17(1):40-6.

78. Jabeen S, Holmboe L, Alnaes GI, Andersen AM, Hall KS, Kristensen VN. Impact of genetic variants of RFC1, DHFR and MTHFR in osteosarcoma patients treated with high-dose methotrexate. Pharmacogenomics J. 2015;15(5):385-90.

79. Passetti F, Ferreira CG, Costa FF. The impact of microRNAs and alternative splicing in pharmacogenomics. Pharmacogenomics J. 2009;9(1):1-13.

80. Chhibber A, French CE, Yee SW, Gamazon ER, Theusch E, Qin X, Webb A, Papp AC, Wang A, Simmons CQ, et al. Transcriptomic variation of pharmacogenes in multiple human tissues and lymphoblastoid cell lines. Pharmacogenomics J. 2017;17(2):137-45.

81. Moitra K, Scally M, McGee K, Lancaster G, Gold B, Dean M. Molecular evolutionary analysis of $A B C B 5$ : the ancestral gene is a full transporter with potentially deleterious single nucleotide polymorphisms. PLOS One. 2011;6(1):e16318.

82. Shihab HA, Gough J, Mort M, Cooper DN, Day IN, Gaunt TR. Ranking nonsynonymous single nucleotide polymorphisms based on disease concepts. Hum Genomics. 2014:8:11.

83. Pinto N, Dolan ME. Clinically relevant genetic variations in drug metabolizing enzymes. Curr Drug Metab. 2011;12(5):487-97.

84. Sim SC, Kacevska M, Ingelman-Sundberg M. Pharmacogenomics of drugmetabolizing enzymes: a recent update on clinical implications and endogenous effects. Pharmacogenomics J. 2013;13(1):1-11.
85. Jacob AG, Smith CWJ. Intron retention as a component of regulated gene expression programs. Hum Genet. 2017;136(9):1043-57.

86. Dvinge $\mathrm{H}$, Bradley RK. Widespread intron retention diversifies most cancer transcriptomes. Genome Med. 2015;7(1):45.

87. Sailaja K, Rao VR, Yadav S, Reddy RR, Surekha D, Rao DN, Raghunadharao D, Vishnupriya S. Intronic SNPS of TP53 gene in chronic myeloid leukemia: impact on drug response. J Nat Sci Biol Med. 2012;3(2):182-5.

88. Wang D, Guo Y, Wrighton SA, Cooke GE, Sadee W. Intronic polymorphism in CYP3A4 affects hepatic expression and response to statin drugs. Pharmacogenomics J. 2011;11(4):274-86.

89. Elens L, Becker ML, Haufroid V, Hofman A, Visser LE, Uitterlinden AG, Stricker $B$, van Schaik RH. Novel CYP3A4 intron 6 single nucleotide polymorphism is associated with simvastatin-mediated cholesterol reduction in the Rotterdam study. Pharmacogenet Genomics. 2011;21(12):861-6.

90. Elens $L$, Bouamar $R$, Hesselink DA, Haufroid V, van der Heiden IP, van Gelder T, van Schaik RH. A new functional CYP3A4 intron 6 polymorphism significantly affects tacrolimus pharmacokinetics in kidney transplant recipients. Clin Chem. 2011;57(11):1574-83.

91. Elens L, Bouamar R, Hesselink DA, Haufroid V, van Gelder T, van Schaik RH The new CYP3A4 intron 6 C>T polymorphism (CYP3A4*22) is associated with an increased risk of delayed graft function and worse renal function in cyclosporine-treated kidney transplant patients. Pharmacogenet Genomics. 2012;22(5):373-80.

92. Matsui M, Corey DR. Non-coding RNAs as drug targets. Nat Rev Drug Discov. 2017;16(3):167-79.

93. Sur I, Taipale J. The role of enhancers in cancer. Nat Rev Cancer. 2016;16(8):483-93.

94. Chen T, Wang Z, Zhou W, Chong Z, Meric-Bernstam F, Mills GB, Chen K. Hotspot mutations delineating diverse mutational signatures and biological utilities across cancer types. BMC Genomics. 2016;17 Suppl 2:394.

\section{Ready to submit your research? Choose BMC and benefit from:}

- fast, convenient online submission

- thorough peer review by experienced researchers in your field

- rapid publication on acceptance

- support for research data, including large and complex data types

- gold Open Access which fosters wider collaboration and increased citations

- maximum visibility for your research: over $100 \mathrm{M}$ website views per year

At BMC, research is always in progress.

Learn more biomedcentral.com/submissions 